\title{
Autism-like behaviors in male mice with a Pcdh19 deletion
}

\author{
Jisoo Lim', Jiin Ryu', Shinwon Kang ${ }^{1}$, Hyun Jong Noh and Chul Hoon Kim ${ }^{1,2^{*}}$ (D)
}

\begin{abstract}
Mutations in protocadherin 19 (PCDH19), which is on the X-chromosome, cause the brain disease Epilepsy in Females with Mental Retardation (EFMR). EFMR is also often associated with autism-like symptoms. In mice and humans, epilepsy occurs only in heterozygous females who have a mixture of PCDH19 wild-type (WT) and mutant cells caused by random X-inactivation; it does not occur in hemizygous PCDH19 mutant males. This unique inheritance pattern strongly suggests the underlying disease mechanism operates via interference between $\mathrm{WT}$ and mutant cells rather than being a result of complete loss of PCDH19 functions. Although it remains unclear whether the other symptoms of EFMR also conform to this unique genotype-phenotype relationship, PCDH19 mutant males were recently reported to demonstrate autism-like symptoms. We, therefore, used a Pcdh19 knockout (KO) mouse model to ask whether a complete lack of PCDH19 causes autism-like behaviors. Consistent with the autism observed in EFMR females, we found Pcdh19 heterozygous KO female mice (with mosaic expression of PCDH19) show defects in sociability in the 3-chamber test. Surprisingly, hemizygous Pcdh19 KO male mice (without any PCDH19 expression) exhibit impaired sociability in the 3chamber test and reduced social interactions in the reciprocal social interaction test. We also observed that, compared to WT mice, mutant mice display more repetitive behaviors, including self-grooming and rearing. These findings indicate that hemizygous Pcdh19 KO male mice show autism-like phenotypes.
\end{abstract}

Epilepsy in Females with Mental Retardation (EFMR) is reportedly caused by mutations (i.e., missense, nonsense, and deletion, etc.) in the X-linked gene protocadherin 19 (PCDH19) [1]. EFMR patients have early-onset seizures frequently associated with varying degrees of intellectual disability (ID) and autism-like symptoms [2-4]. As the name of the disease implies, it is highly sex-limited. Epileptic symptoms appear only in females heterozygous for $P C D H 19$ mutations, whereas males hemizygous for $P C D H 19$ mutations are unaffected carriers [5]. Because $P C D H 19$ is X-linked, it is subject to random $\mathrm{X}$-inactivation, producing mosaic expression in heterozygous mutant females [1]. The identification of male patients affected by postzygotic somatic $P C D H 19$ mutations supports the idea that the disease mechanism is related to mosaic expression of PCDH19 [6, 7]. This idea is further supported by the case of an epileptic patient with Klinefelter Syndrome (47, XXY) heterozygous for a PCDH19 mutation [8]. This unique genotype-phenotype relationship suggests

\footnotetext{
* Correspondence: kimhoon@yuhs.ac

1Department of Pharmacology, BK21 PLUS Project for Medical Science, Brain Research Institute, Yonsei University College of Medicine, Seoul 03722, Korea ${ }^{2}$ Severance Biomedical Science Institute, Yonsei University College of Medicine, Seoul 03722, Korea
}

the symptoms of EFMR emerge from the abnormal interaction of two different populations of brain cells, some with and some without PCDH19 expression. This cellular mechanism is referred to as "cellular interference" $[1,6]$.

Recently, Pederick et al. [9] demonstrated a dramatic and abnormal segregation of PCDH19(+) and PCDH19(-) cells in the developing brains of Pcdh19 heterozygous KO female mice that was well-correlated with seizure-like activities as recorded by electrocorticogram. This result provided the first experimental evidence of cellular interference as a key pathogenic mechanism in EFMR. It is unclear, however, whether autism spectrum disorder (ASD) in EFMR also conforms to both this unusual inheritance pattern and cellular interference mechanism. It is notable that recent human studies identified some males with ASD who have mutations in PCDH19 $[3,10,11]$, suggesting PCDH19 mutations may also play a role in producing the symptoms of males with ASD via mechanisms other than cellular interference. In this study, we investigate this possibility using a Pcdh19 KO mouse model.

Consistent with previous studies $[9,12]$, heterozygous Pcdh19 KO female mice show an abnormal "tigerstriped" pattern of segregation between $\mathrm{PCDH} 19(+)$ and 


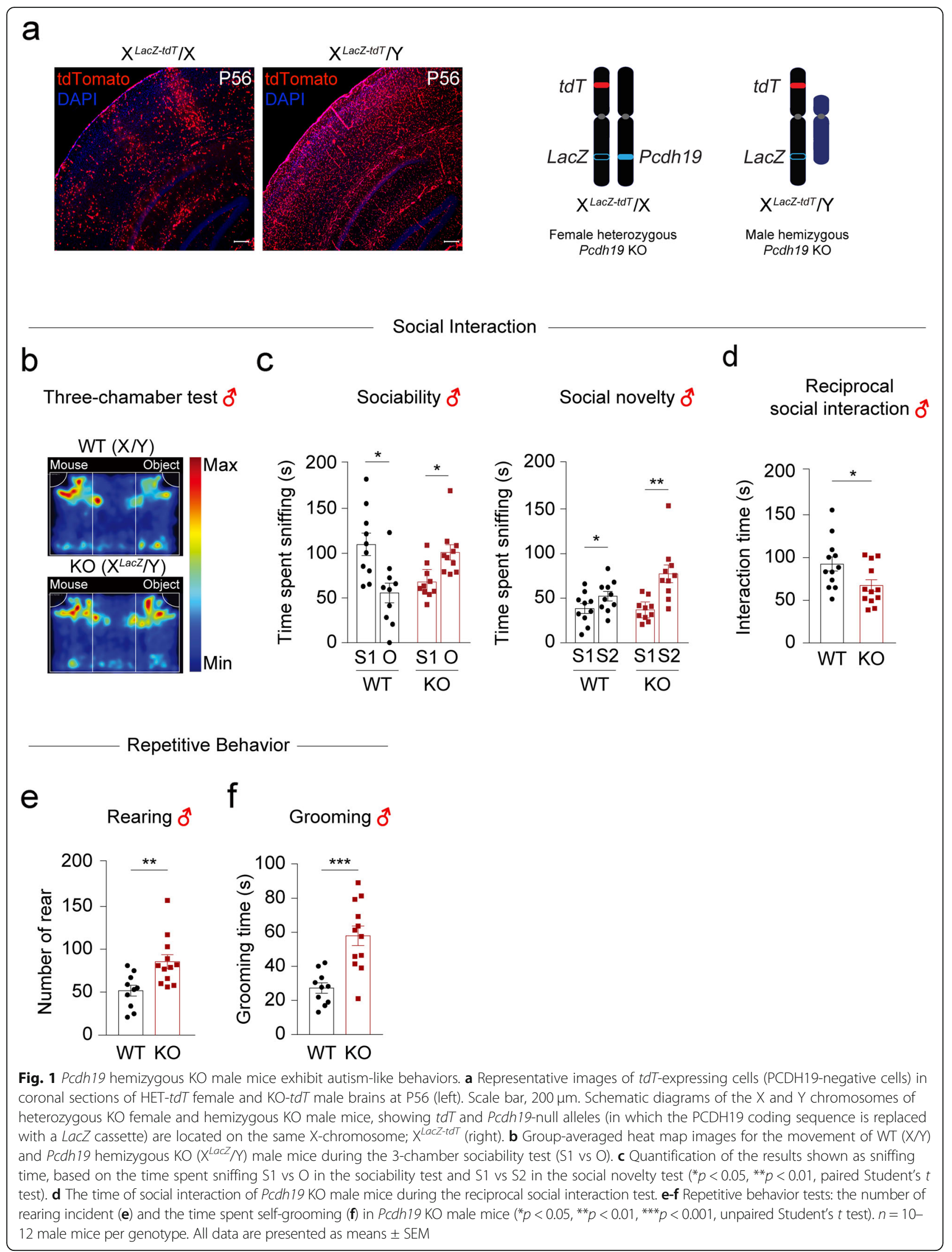


PCDH19(-) cells in the brain (Fig. 1a). In contrast to heterozygous Pcdh19 KO female mice, we did not observe a similar segregation in hemizygous Pcdh19 KO male mice, despite both having a tdTomato $(t d T)$ reporter gene on the X-chromosome where the Pcdh19 gene was deleted (Fig. 1a). This finding suggests any phenotypes in hemizygous Pcdh19 KO male mice are independent of the abnormal sorting mechanism observed in heterozygous Pcdh19 KO female mice.

First, we asked whether heterozygous Pcdh19 KO female mice show autism-like behaviors in our experimental setting (see Additional file 1 for the detailed methods). We found that heterozygous Pcdh19 KO female mice (X ${ }^{\operatorname{LacZ}}$ / $\mathrm{X}$ ) do not show any preference toward exploring a novel mouse (S1) versus a non-social novel object $(\mathrm{O})$ in the 3chamber test (the sociability test). This suggests heterozygous Pcdh19 KO female mice recapitulate the autism-like symptoms of female EFMR patients. In the social novelty test, in which we measured preference toward a familiar mouse (S1) and a novel mouse (S2), we found the heterozygous Pcdh19 KO mice $\left(\mathrm{X}^{\mathrm{LacZ}} / \mathrm{X}\right)$ spend more time exploring the novel mouse (S2) (see Additional file 2).

We next examined the male mice to determine whether they also show any social impairment. In the 3chamber sociability test, we found male Pcdh19 KO $\left(\mathrm{X}^{\mathrm{LacZ}} / \mathrm{Y}\right)$ mice spend significantly more time sniffing a non-social novel object $(\mathrm{O})$ rather than a novel mouse (S1), suggesting abnormal sociality. Both hemizygous males and controls, however, show similar preference towards a novel mouse (S2) in the social novelty test (Fig. $1 \mathrm{~b}-\mathrm{c})$. We then measured reciprocal social interactions to confirm the social abnormalities of male Pcdh19 KO $\left(\mathrm{X}^{\mathrm{LacZ}} / \mathrm{Y}\right)$ mice. We found they spend significantly less time interacting with a stranger mouse than WT $(\mathrm{X} / \mathrm{Y})$ mice do (Fig. 1d). To determine whether male Pcdh19 $\mathrm{KO}\left(\mathrm{X}^{\mathrm{LacZ}} / \mathrm{Y}\right)$ mice show increased repetitive behavioranother autism-like phenotype-we monitored their rearing and stereotyped grooming behaviors. We found Pcdh19 $\mathrm{X}^{\text {LacZ }} / \mathrm{Y}$ male mice spend more time rearing and self-grooming (Fig. 1e-f) than WT $(X / Y)$ male mice. Thus, their abnormal social interaction results and increased repetitive behaviors suggest hemizygous Pcdh19 $\mathrm{KO}\left(\mathrm{X}^{\text {LacZ }} / \mathrm{Y}\right)$ mice show autism-like behaviors.

We do not yet know how the complete loss of Pcdh19 causes autism-like behaviors in male mice, but considering the fact that the abnormal segregation pattern occurs only in the brain of female heterozygous Pcdh19 KO mice $[9,13]$, but not in male $\mathrm{KO}$ mice, our present findings suggest the mechanism will be distinct from the cellular interference mechanism that underlies the epileptic symptoms of EFMR. It is possible a loss of PCDH19mediated cell-to-cell adhesion may contribute to autismlike behaviors in hemizygous Pcdh19 male KO mice. PCDH19 regulates intracellular binding proteins like
NONO and the $\mathrm{GABA}_{\mathrm{A}}$ receptor alpha subunits [14, 15]. Hence, it is also possible the absence of PCDH19 disrupts the function of unidentified autism-related binding proteins. Our social interaction results were inconsistent with a previous study in which heterozygous $\mathrm{KO}$ female and hemizygous $\mathrm{KO}$ male mice showed no abnormalities in the social interaction tests [12]. In fact, we are still unclear why the mice showed this inconsistency, but we found that the background of the mouse, the targeted exons, and the size of the behavioral apparatus used for the experiment were all different.

This is the first report showing, in genetically modified mice, that autism-like behaviors induced by Pcdh19 mutations are not subject to the same genotype-phenotype relationship observed in epileptic symptoms of EFMR. From this finding, we postulate that both mosaic expression of $P C D H 19$ and $P C D H 19$ insufficiency contribute to the pathogenesis of EFMR. Considering the fact that male patients affected by mosaic PCDH19 mutations also show autism [6], the induction of autism in a male patient may not require complete loss of PCDH19 in every cell. In the future, the generation of male mice with mosaic Pcdh19 deletions will help address the question of whether both mosaic loss and complete loss of $P C D H 19$ result in autism-like behaviors.

\section{Supplementary information}

Supplementary information accompanies this paper at https://doi.org/10. 1186/s13041-019-0519-3.

Additional file 1. Materials and Methods.

Additional file 2: Figure S1. Pcdh19 heterozygous KO female mice display autistic-like behaviors in the 3-chamber sociability test.

Abbreviations

ASD: Autism spectrum disorder; EFMR: Epilepsy in females with mental retardation; ID: Intellectual disability; KO: Knockout; PCDH19: Protocadherin 19; SEM: Standard error of the mean; tdT: tdTomato; WT: Wild-type

\section{Acknowledgements}

Not applicable.

Authors' contributions

CHK conceptualized and designed the research. JL, JR, SK, HJN conducted the behavioral experiments. CHK, JL analyzed, interpreted the data. CHK, JL prepared the manuscript. All authors read and approved the final manuscript.

Authors' information

Not applicable.

Funding

This work was supported by the National Research Foundation of Korea (NRF) grant funded by the Korean government (MSIT) (NRF-2019R1A2C3002354) and a faculty research grant of Yonsei University College of Medicine for 2013 (6-20130072).

Availability of data and materials

All data and materials are available upon requests. 


\section{Ethics approval}

All animal experiments were performed in compliance with guidelines approved by the Institutional Animal Care and Use Committee (IACUC) of Yonsei University Health System (reference number: 2018-0285).

\section{Consent for publication}

Not applicable.

\section{Competing interests}

The authors declare that they have no competing interests.

Received: 13 June 2019 Accepted: 30 October 2019

Published online: 20 November 2019

\section{References}

1. Dibbens LM, Tarpey PS, Hynes K, Bayly MA, Scheffer IE, Smith R, et al. Xlinked protocadherin 19 mutations cause female-limited epilepsy and cognitive impairment. Nat Genet. 2008;40(6):776-81.

2. Specchio N, Marini C, Terracciano A, Mei D, Trivisano M, Sicca F, et al. Spectrum of phenotypes in female patients with epilepsy due to protocadherin 19 mutations. Epilepsia. 2011;52(7):1251-7.

3. Scheffer IE, Turner SJ, Dibbens LM, Bayly MA, Friend K, Hodgson B, et al. Epilepsy and mental retardation limited to females: an under-recognized disorder. Brain. 2008;131(Pt 4):918-27.

4. Hynes K, Tarpey P, Dibbens LM, Bayly MA, Berkovic SF, Smith R, et al. Epilepsy and mental retardation limited to females with PCDH19 mutations can present de novo or in single generation families. J Med Genet. 2010; 47(3):211-6.

5. Ryan SG, Chance PF, Zou CH, Spinner NB, Golden JA, Smietana S. Epilepsy and mental retardation limited to females: an X-linked dominant disorder with male sparing. Nat Genet. 1997;17(1):92-5.

6. Depienne C, Bouteiller D, Keren B, Cheuret E, Poirier K, Trouillard O, et al. Sporadic infantile epileptic encephalopathy caused by mutations in PCDH19 resembles Dravet syndrome but mainly affects females. PLoS Genet. 2009; 5(2):e1000381.

7. de Lange IM, Rump P, Neuteboom RF, Augustijn PB, Hodges K, Kistemaker $A l$, et al. Male patients affected by mosaic PCDH19 mutations: five new cases. Neurogenetics. 2017;18(3):147-53.

8. Romasko EJ, DeChene ET, Balciuniene J, Akgumus GT, Helbig I, Tarpinian JM, et al. PCDH19-related epilepsy in a male with Klinefelter syndrome: additional evidence supporting PCDH19 cellular interference disease mechanism. Epilepsy Res. 2018;145:89-92.

9. Pederick DT, Richards KL, Piltz SG, Kumar R, Mincheva-Tasheva S, Mandelstam SA, et al. Abnormal Cell Sorting Underlies the Unique X-Linked Inheritance of PCDH19 Epilepsy. Neuron. 2018;97(1):59-66.e5.

10. Piton A, Gauthier J, Hamdan FF, Lafreniere RG, Yang Y, Henrion E, et al. Systematic resequencing of $\mathrm{X}$-chromosome synaptic genes in autism spectrum disorder and schizophrenia. Mol Psychiatry. 2011;16(8):867-80.

11. van Harssel JJ, Weckhuysen S, van Kempen MJ, Hardies K, Verbeek NE, de Kovel CG, et al. Clinical and genetic aspects of PCDH19-related epilepsy syndromes and the possible role of PCDH19 mutations in males with autism spectrum disorders. Neurogenetics. 2013;14(1):23-34.

12. Hayashi S, Inoue Y, Hattori S, Kaneko M, Shioi G, Miyakawa T, et al. Loss of X-linked Protocadherin-19 differentially affects the behavior of heterozygous female and hemizygous male mice. Sci Rep. 2017;7(1):5801.

13. Pederick DT, Homan CC, Jaehne EJ, Piltz SG, Haines BP, Baune BT, et al. Pcdh19 loss-of-function increases neuronal migration in vitro but is dispensable for brain development in mice. Sci Rep. 2016;6:26765.

14. Bassani S, Cwetsch AW, Gerosa L, Serratto GM, Folci A, Hall IF, et al. The female epilepsy protein PCDH19 is a new GABAAR-binding partner that regulates GABAergic transmission as well as migration and morphological maturation of hippocampal neurons. Hum Mol Genet. 2018;27(6):1027-38.

15. Pham DH, Tan CC, Homan CC, Kolc KL, Corbett MA, McAninch D, et al. Protocadherin 19 (PCDH19) interacts with paraspeckle protein NONO to coregulate gene expression with estrogen receptor alpha (ERalpha). Hum Mol Genet. 2017;26(11):2042-52.

\section{Publisher's Note}

Springer Nature remains neutral with regard to jurisdictional claims in published maps and institutional affiliations.

\section{Ready to submit your research? Choose BMC and benefit from}

- fast, convenient online submission

- thorough peer review by experienced researchers in your field

- rapid publication on acceptance

- support for research data, including large and complex data types

- gold Open Access which fosters wider collaboration and increased citations

- maximum visibility for your research: over $100 \mathrm{M}$ website views per year

At BMC, research is always in progress.

Learn more biomedcentral.com/submissions 